\title{
Olfactory Learning in Individually Assayed Drosophila Larvae
}

\author{
Sabine Scherer, ${ }^{1}$ Reinhard F. Stocker, ${ }^{1}$ and Bertram Gerber ${ }^{1,2,3}$ \\ ${ }^{1}$ University of Fribourg, Department of Biology \& Program in Neuroscience, CH 1700 Fribourg, Switzerland; ${ }^{2}$ University of Würzburg, Institute \\ of Genetics and Neurobiology, Biocenter, D 97074 Würzburg, Germany
}

\begin{abstract}
Insect and mammalian olfactory systems are strikingly similar. Therefore, Drosophila can be used as a simple model for olfaction and olfactory learning. The brain of adult Drosophila, however, is still complex. We therefore chose to work on the larva with its yet simpler but adult-like olfactory system and provide evidence for olfactory learning in individually assayed Drosophila larvae. We developed a differential conditioning paradigm in which odorants are paired with positive ("+" fructose) or negative ("-" quinine or sodium chloride) gustatory reinforcers. Test performance of individuals from two treatment conditions is comparedone received odorant $\mathrm{A}$ with the positive reinforcer and odorant $\mathrm{B}$ with a negative reinforcer $(\mathrm{A}+/ \mathrm{B}-)$; animals from the other treatment condition were trained reciprocally $(\mathrm{A}-/ \mathrm{B}+)$. During test, differences in choice between $\mathrm{A}$ and $\mathrm{B}$ of individuals having undergone either $\mathrm{A}+\mathrm{B}-$ or $\mathrm{A}-\mathrm{B}+$ training therefore indicate associative learning. We provide such evidence for both combinations of reinforcers; this was replicable across repetitions, laboratories, and experimenters. We further show that breaks improve performance, in accord with basic principles of associative learning. The present individual assay will facilitate electrophysiological studies, which necessarily use individuals. As such approaches are established for the larval neuromuscular synapse, but not in adults, an individual larval learning paradigm will serve to link behavioral levels of analysis to synaptic physiology.
\end{abstract}

Associative learning is crucial to animals as, in the case of Pavlovian conditioning, it enables them to predict important events such as the occurrence of food, predators, social partners, or changes in evironmental conditions. Such predictions then allow preparatory behavior of potentially vital importance. An integrated understanding of such Pavlovian conditioning is facilitated if it can be studied on many levels of analysis. Also, it is desirable to use an organism that is relatively simple yet keeps key features of more complex organisms. The fruit fly Drosophila melanogaster is one of the model systems to meet these demands. On the level of gene homology, flies and mammals share surprisingly many genes (Rubin et al. 2000), suggesting that the molecular mechanisms of behavioral plasticity might be shared. It offers the possibility of relating analyses from the genetic, molecular, electrophysiological, and network levels to behavior (Sokolowski 2001). Together with the possibilities to manipulate Drosophila using transgenic techniques, the advances in the behavioral analysis of associative learning (Heisenberg et al. 2001) make this system a promising candidate for an integrative understanding of associative function. This is in particular true for olfaction (Stocker 1994; 2001; Vosshall 2001) and olfactory learning (Waddell and Quinn 2001; Zars 2001).

${ }^{3}$ Corresponding author.

E-MAIL bertram.gerber@biozentrum.uni-wuerzburg.de; FAX 499318884452.

Article and publication are at http://www.learnmem.org/cgi/doi/ $10.1101 / \mathrm{lm} .57903$
Notably, a number of studies have focused recently on larval Drosophila, likely because of their reduced cell number (Lilly and Carlson 1990; Tissot et al. 1997; Cobb 1999; Heimbeck et al. 1999; Cobb and Domain 2000; Oppliger et al. 2000; Scott et al. 2001; Python and Stocker 2002a,b; Liu et al. 2003). That is, Drosophila larvae possess only 21 pairs of olfactory (and $\sim 80$ pairs of gustatory) receptor neurons, compared with the 1300 pairs of olfactory (and $\sim 650$ pairs of gustatory) receptor neurons in the adult fly (Stocker 1994, 2001). In Figure 1, A and B, we give an overview of the anatomical organization of the larval cephalic chemosensory system. The reduced cell number combines with the otherwise adult-like complexity of central olfactory processing to make larval Drosophila a useful model system. This is true also in perspective to mammals, which show a striking similarity in key features of their olfactory system with that of insects (Boeckh et al. 1990; Hildebrand and Shepherd 1997), including, of course, the olfactory system of Drosophila larvae.

With respect to olfactory associative learning, relatively little is known about larval Drosophila. This is unfortunate, as our knowledge concerning the physiological mechanisms of synaptic plasticity largely derives from experiments in the larva (Koh et al. 2000). The learning experiments by Aceves-Piña and Quinn (1979), Heisenberg et al. (1985), Tully and co-workers (1994), and Dukas (1998) employed en masse assays which, as such, preclude approaches to combine behavior and physiology. Therefore, we sought to establish an olfactory learning paradigm that

LEARNING \& MEMORY 10:217-225 @ 2003 by Cold Spring Harbor Laboratory Press ISSN1072-0502/03 \$5.00

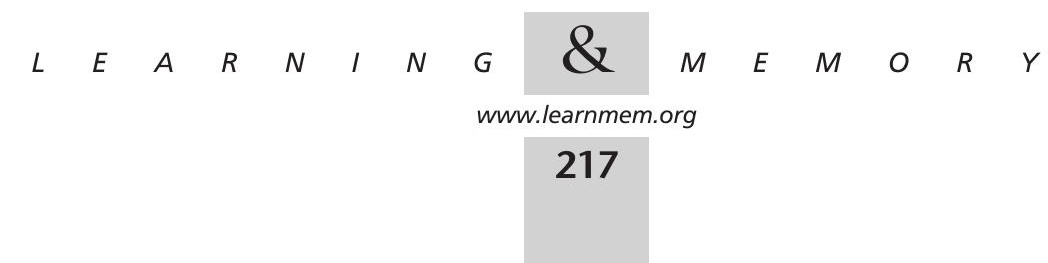


A
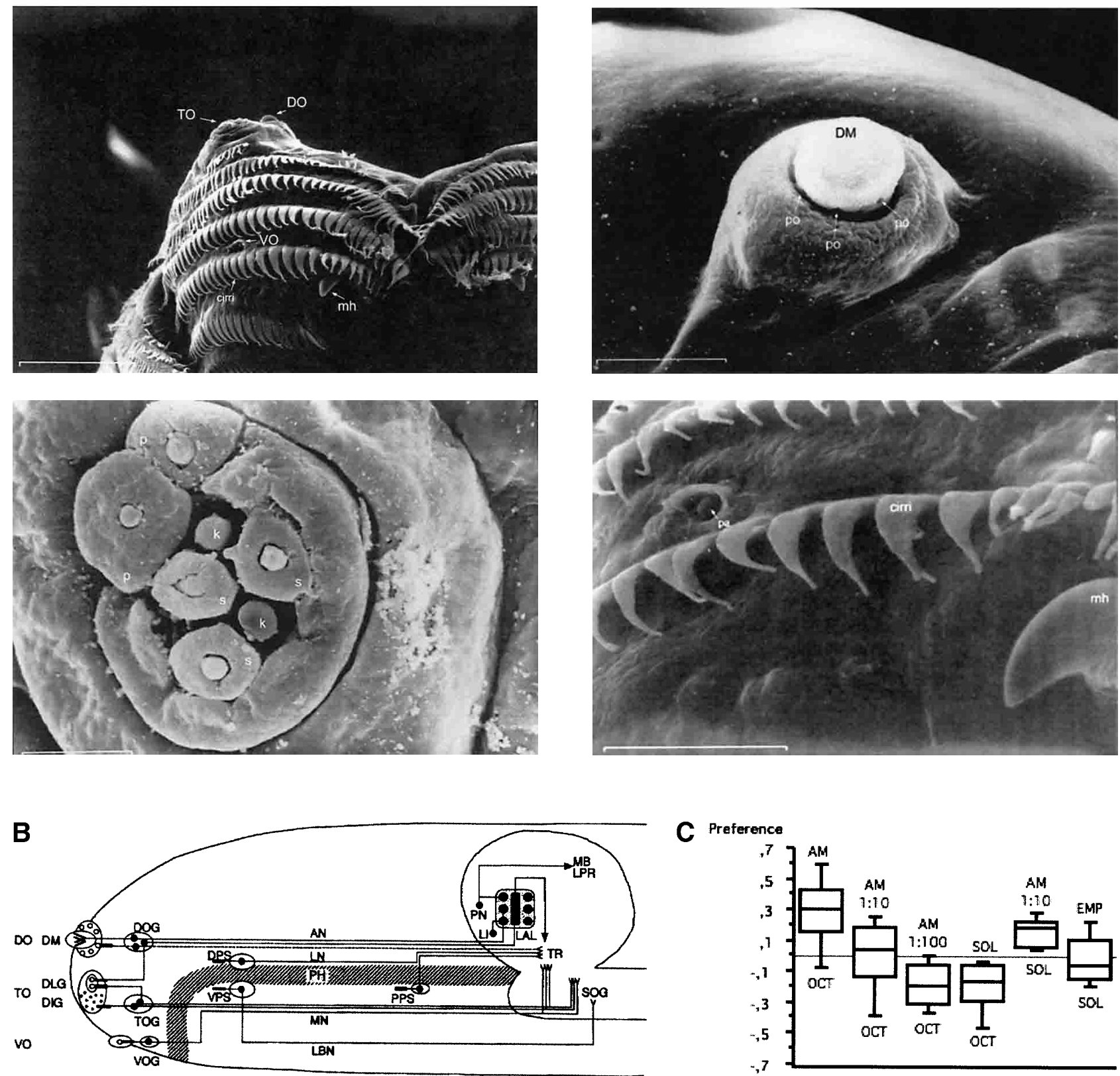

C Preference

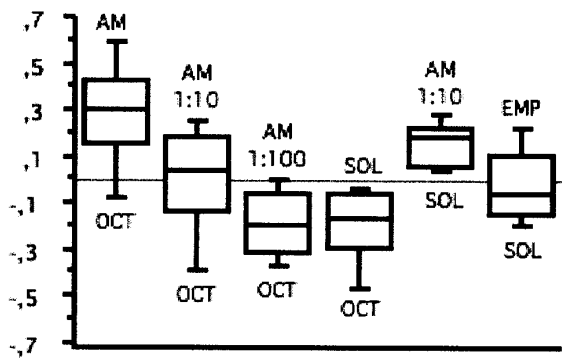

Figure 1 (A) S.E.M. images of the external chemosensory organs of the larval head; these include an overview as well as dorsal, terminal, and ventral organ (DO, TO, VO). $\mathrm{VO}$ and $\mathrm{TO}$ likely have gustatory function, whereas the DO serves both gustatory and olfactory function. (mh) mouth hook; (p) big, (k) knob, and (s) small sensilla of TO; (pa) papilla of VO; (po) pores of the dome (DM). (B) Schematic (from Python and Stocker 2002a) showing the central projections of the head chemosensory organs to the antennal lobe (AL), tritocerebrum (TR), and suboesophageal ganglion (SOG). From the AL, projection neurons $(\mathrm{PN})$ relay onto the lateral protocerebrum (LPR) and provide collaterals into the mushroom bodies (MB). (AN) Antennal, (LN) labral, (MN) maxillary, and (LBN) labial nerves. (DLG) Dorsolateral and (DIG) distal group of TO. (DOG) Ganglia of DO, (TOG) TO, and (VOG) VO. (DPS) Dorsal, (VPS) ventral, and (PPS) posterior pharyngeal sensilla. Both $A$ and $B$ do not cover other potentially chemosensitive structures on cephalic, thoracic, and abdominal segments (Kankel et al. 1980; Singh and Singh 1984). (C) Results of Experiment 1 testing for odor preferences in an en masse assay. The preferences for conditions of choice between (from left to right) undiluted AM versus OCT, AM $10^{-1}$ versus OCT, AM $10^{-2}$ versus OCT, SOL (solvent: paraffin oil) versus OCT, AM 10 versus SOL, EMP (empty container) versus SOL are shown; in all cases, undiluted OCT was used. Positive values indicate a preference for the respective former stimulus, negative values indicate preference for the respective latter stimulus. Box plots represent medians as the middle line; boxes and whiskers indicate $25 \%, 75 \%$ and $10 \%, 90 \%$ quantiles, respectively. For statistics, see text.

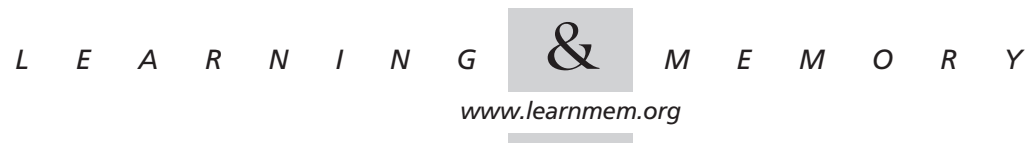


uses individually assayed larvae. Different from Aceves-Piña and Quinn (1979), Heisenberg et al. (1985), and Tully et al. (1994), we did not use electric shock but rather gustatory stimuli as reinforcement. This is because (1) efforts to reproduce electric shock learning yielded negative results (Forbes 1993; F. Python, pers. comm.); (2) we wanted to capitalize on the emerging knowledge on the gustatory system (Singh and Singh 1984; Singh 1997; Tissot et al. 1997; Heimbeck et al. 1999; Mitchell et al. 1999; Scott et al. 2001; Smith 2001; Python and Stocker 2002a,b), which will facilitate future analyses of the neuronal pathways to mediate reinforcement; (3) gustatory reinforcement, but not electric shock, is of potential biological relevance for larval Drosopbila; (4) the intimate interplay between the central projections of smell and taste (Python and Stocker 2001a,b) made us suspect that it might be easy for the larva to associate stimuli from these two modalities. Using olfactory stimuli and gustatory reinforcement, we were for the first time able to demonstrate associative learning in individually assayed Drosophila larvae. This is nicely complemented by a concurrently developed visual learning paradigm for the larva (B. Gerber, S. Scherer, K. Neuser, B. Michels, T. Hendel, R.F. Stocker, and M. Heisenberg, in prep.).

\section{MATERIALS AND METHODS}

\section{Principle of Learning Experiments}

In each learning experiment, we compared individual animals that underwent either of two training regimes-one received amylacetate (AM) with a positive reinforcer and 1-octanol (OCT) with a negative reinforcer (AM+/OCT-); the second was trained reciprocally (AM-/OCT+). Then, animals from both treatment conditions were individually tested in a choice situation for their preference between AM versus OCT. Associative learning would be indicated by systematic differences of individuals from either treatment condition during test. Specifically, we predicted a higher preference for $\mathrm{AM}$ in animals that underwent $\mathrm{AM}+/ \mathrm{OCT}-$ training as compared with AM-/OCT+ training. The conclusion regarding associativity is inescapable as during training individuals from both treatment conditions had identical exposure to either odorant as well as to either reinforcer-what differed between treatment conditions is only the contigency between a particular odor and the particular reinforcer.

\section{Flies}

Flies were of the Canton-S wild-type strain kept in mass culture and maintained in the laboratory at $25^{\circ} \mathrm{C}$ and a $12 / 12 \mathrm{~h}$ light/dark cycle (Experiments 1-4B, performed in Fribourg). Experiments 4C and $4 \mathrm{D}$ were performed in Würzburg, and flies were kept in the local fly facilities at $25^{\circ} \mathrm{C}, 60 \%-70 \%$ relative humidity and a $14 / 10 \mathrm{~h}$ light/ dark cycle.

Daily, flies were transferred into a fresh food bottle where they could lay eggs until the following day when they were transferred to a fresh bottle once again. Experiments were performed at $108 \mathrm{~h}$ after beginning of the egg laying period; therefore, experimental larva were aged 84-108 $\mathrm{h}$ after egg laying, which is before the "wandering" stage begins ( $110 \mathrm{~h}$ after egg laying; Sawin-McCormack et al. 1995). For experiments, a spoonful of food medium containing larvae was taken from the food bottle and transferred to a glass vial. From there, medium-sized, moving individual animals were taken on demand, briefly washed in a vial containing tap water and immediately transferred to the assay plates for the start of experiments.

\section{Petridishes, Odors, Reinforcers}

Each day before experiments, petridish assay plates were freshly prepared. After boiling, agarose was allowed to cool down for 30 min. Then, petridishes (Experiment 1-4B: Greiner, Frickenhausen, D; Experiment 4C and 4D: Sarstedt, Nümbrecht, D) with 85-mm inner diameter were filled with a thin layer of $1 \%$ agarose (electrophoresis grade; Roth, Karlsruhe, D). After agarose was added, it was allowed to solidify for $2 \mathrm{~h}$. Then, lids were put on the plates to avoid drying out and plates were left untreated at room temperature until the following day.

As olfactory stimuli, we used OCT (purity: 99.5\%) and AM (purity: 99\%); dilutions of AM (see below) were prepared in paraffin oil. As potentially negative gustatory reinforcers, we used either quinine hemisulfate (QUI, purity: $92 \%$ ) or $\mathrm{NaCl}(\mathrm{NaCl}$, purity: $99.5 \%$ ), and as a potentially positive reinforcer we used fructose (FRU, purity: 99\%). These reinforcers were added to the agarose 10 min after boiling to reach final concentrations of $0.2 \%$ QUI, $2 \mathrm{M}$ $\mathrm{NaCl}$, or $1 \mathrm{M}$ FRU in the plates. Chemicals were obtained from Aldrich (AM), Sigma (FRU, QUI), and Fluka (OCT, NaCl, paraffin oil).

\section{Experimental Setup}

All experiments were performed in red light under a fume hood. Room temperature ranged between $20^{\circ} \mathrm{C}$ and $24^{\circ} \mathrm{C}$ for Experiments $1-4 \mathrm{~B}$ and between $23^{\circ} \mathrm{C}$ and $25^{\circ} \mathrm{C}$ for Experiment $4 \mathrm{C}$ and 4D. Immediately before experiments, we replaced the regular lids of the petri dishes with lids perforated in the center by $151-\mathrm{mm}$ holes to improve exhaustion of odorant from the assay plates. These plates were filled with solidified agarose (see above); during the training trials, we used plates that additionally contained gustatory reinforcers. No such gustatory reinforcers were added for test trials. The reinforcers used were either QUI or $\mathrm{NaCl}$ during "negative" trials and FRU during "positive" trials.

Odorant was applied by adding $10 \mu \mathrm{L}$ of odor substance (either pure OCT, or $10^{-1} \mathrm{AM}$ in Experiments 2-4B; either pure OCT or $2 \times 10^{-2} \mathrm{AM}$ for Experiment $4 \mathrm{C}, \mathrm{D}$ ) into teflon containers (inner diameter $5 \mathrm{~mm}$ ) that could be closed by a perforated lid (seven holes, $0.5-\mathrm{mm}$ diameter). These containers were placed on opposite sides of the plate $7 \mathrm{~mm}$ from the edges. During training trials, we supplied both containers with the same odorant. In contrast, during test trials left and right containers were loaded with different odorants to create the desired choice situation.

\section{Training and Test}

Animals underwent either of two treatment conditions: Under one treatment condition, AM was paired with the positive and OCT with a negative reinforcer (AM+/OCT-), whereas the other was treated reciprocally $(\mathrm{AM}-/ \mathrm{OCT}+)$. Both treatment conditions were run alternately. To avoid experimenter bias, the experimenter was blind with respect to the chemical identity of odors and reinforcers-that identity was revealed only after the experiment.

Each training trial lasted $1 \mathrm{~min}$. Immediately before a trial, two containers with AM were placed onto the agarose in the assay plate. For half of the animals we started with OCT, and for the other half with AM. For half of the animals within each of these sub-treatment conditions, we started with the positive reinforcer added to the

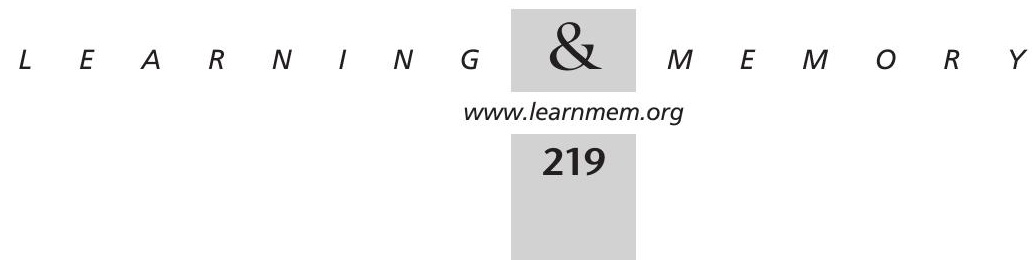


substrate, and for the other half with either of the negative reinforcers. Four larvae were transferred together to the center of the plate using a paintbrush. Then, the lid was closed and the larvae were allowed to freely move for $1 \mathrm{~min}$. After $50 \mathrm{sec}$, two containers with the alternative odorant were put on a second assay plate containing the respective other reinforcer. The larvae were then transferred to that second assay plate, the lid was closed and the larvae could again freely move for $1 \mathrm{~min}$. This cycle of two differential training trials was repeated 10 times. Fresh assay plates were used for each trial. As there were no breaks between trials, this procedure is called temporally "massed" training.

After this training, each larva was individually tested for its odor preference on a separate assay plate; therefore, animals were trained in groups of four, but tested as individuals. For the test, each larva was placed on a fresh, pure agarose assay plate with a container of AM on one side and one of OCT on the other side; sides were changed for every other animal. The larva was placed in the center of the petri dish, the lid was closed and the position of the larva was noted every $20 \mathrm{sec}$ for $5 \mathrm{~min}$ (or once a minute, Experiments 4A,B). Positions were defined as "neutral" (a 7-mm wide zone in the middle of the assay plate), "AM" or "OCT" (see below). Those few larvae that moved onto the lid or onto the odorant containers ( $<5 \%$ of animals) were discarded.

\section{Data Analysis and Statistics}

We provide two kinds of analysis, the first resolved by time, the second by individual. First, for each time point we calculated the proportion of animals on the AM side (P $[\mathrm{AM}]$ ) as the number of animals on the AM side minus the number of animals on the OCT side, divided by the total of larvae, including the ones that we located in the neutral zone:

$$
\mathrm{P}(\mathrm{AM})=\left(\mathrm{N}_{\mathrm{AM}}-\mathrm{N}_{\mathrm{OCT}}\right) /\left(\mathrm{N}_{\mathrm{AM}}+\mathrm{N}_{\mathrm{OCT}}+\mathrm{N}_{\mathrm{NEUT}}\right)
$$

Therefore, positive values indicate that the majority of animals is located on the AM side, whereas negative values indicate their localization on the OCT side.

Second, for each individual we calculated a preference value $\left(\mathrm{PREF}_{\mathrm{AM}}\right)$ as the number of times that animal was counted on the AM side minus the number of times that animal was counted on the OCT side, divided by the total number of counts, including counts in the neutral zone:

$$
\begin{aligned}
\text { PREF }_{\mathrm{AM}}= & \left(\text { Counts }_{\mathrm{AM}}-\text { Counts }_{\mathrm{OCT}}\right) /\left(\text { Counts }_{\mathrm{AM}}\right. \\
& \left.+ \text { Counts }_{\mathrm{OCT}}+\text { Counts }_{\mathrm{NEUT}}\right)
\end{aligned}
$$

Therefore, positive values indicate an $\mathrm{AM}$ preference of a given individual and negative values an OCT preference. The $\mathrm{PREF}_{\mathrm{AM}}$ values are then represented by box plots (with medians as middle line, and $25 \%, 75 \%$, and $10 \%$, and $90 \%$ quantiles, respectively, as box boundaries and whiskers) and statistically compared by MannWhitney U-tests with significance level $P<0.05$. All conclusions remain unaltered if unpaired $t$-tests are used. Also, as the reciprocal training regimes were run alternately, a pairing of animals is possible; conclusions remain unaltered if paired parametric or nonparametric tests are used.

The practice of discarding animals from the neutral zone as done in some previous studies that used mass assays likely was motivated by the fact that in mass assays, larvae often hesitate to disperse and remain in a clump. Interestingly, wild-type strains that disperse slowly in an X-plate photo-behavior assay do not seem to show a photoresponse if tested en masse; however, a photoresponse can be uncovered if animals are tested individually
(Gordesky-Gold et al. 1996). This suggests that individual assays can pick up abilities that mass assays cannot and that in mass assays behavior is likely not independent between individuals. Discarding animals located in the neutral zone seems reasonable as one might hold that these animals "did not decide"; however, such discarding might overestimate preferences, which we sought to avoid.

\section{An Attempt to Balance Odorant Preferences}

In general, odors are attractive to Drosophila larvae (Cobb 1999). Pilot experiments suggested a massive preference for AM over OCT when both were presented in a choice assay. Therefore, we sought to dilute AM to an extent that would yield approximatively equal preference for AM and OCT. These experiments were performed in an en masse assay. All procedures follow the ones outlined above, unless mentioned otherwise.

Food medium containing larvae was transferred to a glass bottle and gently mixed with tap water to wash the animals from the food. Floating larvae were collected with a perforated spoon and rinsed twice with tap water. We transferred 40-70 larvae onto the center of the assay plate, closed the lid, and let the larvae freely move about the plate. The substances to be tested (see below) were located on opposing sides of the assay plate. After $5 \mathrm{~min}$, a preference index was calculated as the number of larvae on the AM half of the plate minus the number of larvae on the OCT side divided by the total number of larvae tested. Statistical analyses used sign tests.

Undiluted OCT was tested against either undiluted, 10-fold diluted, or 100-fold diluted AM. To test detectability, OCT and AM $\left(10^{-1}\right)$ were also tested against solvent (paraffin oil); to test for effects of the solvent, paraffin oil was tested against an empty container.

\section{Electron Microscopy}

Larvae were rinsed five times in water, cooled to immobility and the last segment was cut off. Then, larvae were fixed overnight in $6.25 \%$ glutaraldehyde with $0.1 \mathrm{M}$ Sörensen phosphate buffer $(\mathrm{pH}$ 7.4). Fixed specimens were washed five times in buffer for $5 \mathrm{~min}$ each and dehydrated with a graded series of acetone. After critical point drying in $\mathrm{CO}_{2}$ (BALTEC CPD 030), larvae were mounted on a table and sputtered with Pt/Pd (BALZERS UNION sputter). Specimens were viewed with a scanning electron microscope (Zeiss DSM 962, Oberkochen, D).

\section{RESULTS}

\section{Experiment 1: Balancing Odor Preferences}

Before turning to the learning experiments, we sought to approximate suitable odorant concentrations for our study. Therefore, larvae were tested en masse in an olfactory choice assay. It turned out that larvae preferred undiluted AM over undiluted OCT (Fig. 1C; $N=15 ; P<0.05$; sign test); if $10^{-1} \mathrm{AM}$ was used, they distributed equally on both sides of the assay plate (Fig. $1 \mathrm{C} ; N=25 ; P>0.05$; sign test); if AM was diluted further to $10^{-2}$, preference changed toward OCT (Fig. 1C; $N=16 ; P<0.05$; sign test). Therefore we chose undiluted OCT and $10^{-1} \mathrm{AM}$ as conditioned stimuli for the subsequent learning experiments. To test whether either substance is detectable under these conditions, we tested both of them against solvent (SOL; paraffin

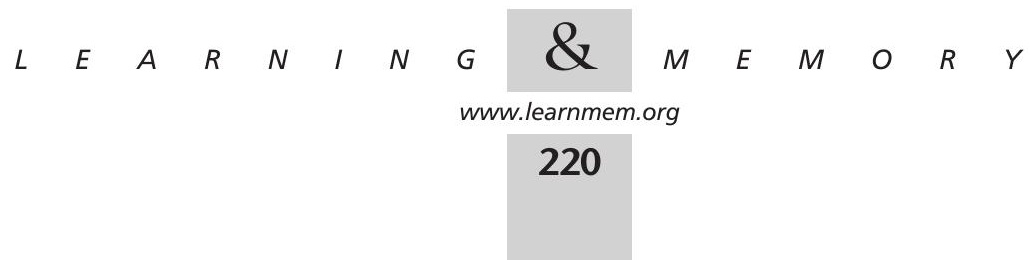


oil). In both cases, larvae preferred the odorant side (Fig. 1C; for AM versus SOL: $N=15 ; P<0.05$; for SOL versus OCT $N=16 ; P<0.05$; sign tests). When we tested solvent against an empty container (EMP), larvae distributed equally on both sides of the assay plate (Fig. 1C; $N=15 ; P>0.05$; sign test) indicating that the solvent does not significantly contribute to behavior under these circumstances.

\section{Experiment 2: Quinine and Fructose as Reinforcers}

We used fructose (FRU; +) and quinine hemisulfate (QUI;-) as reinforcers and AM and OCT as conditioned stimuli. Larvae that received positive reinforcement with AM and negative reinforcement with OCT (AM+/OCT-) showed a higher preference for AM during the 300-sec test period than larvae from the companion treatment condition that received reciprocal training (AM-/OCT+) (Fig. $2 \mathrm{~A} ; N_{1}=95$, $\left.N_{2}=99 ; U=3023 ; P<0.05\right)$. This suggests an associative learning process between olfactory stimuli and gustatory reinforcement. To gain confidence in this result, we repeated the experiment and found also in this repetition a higher preference for AM after AM+/OCT- as compared
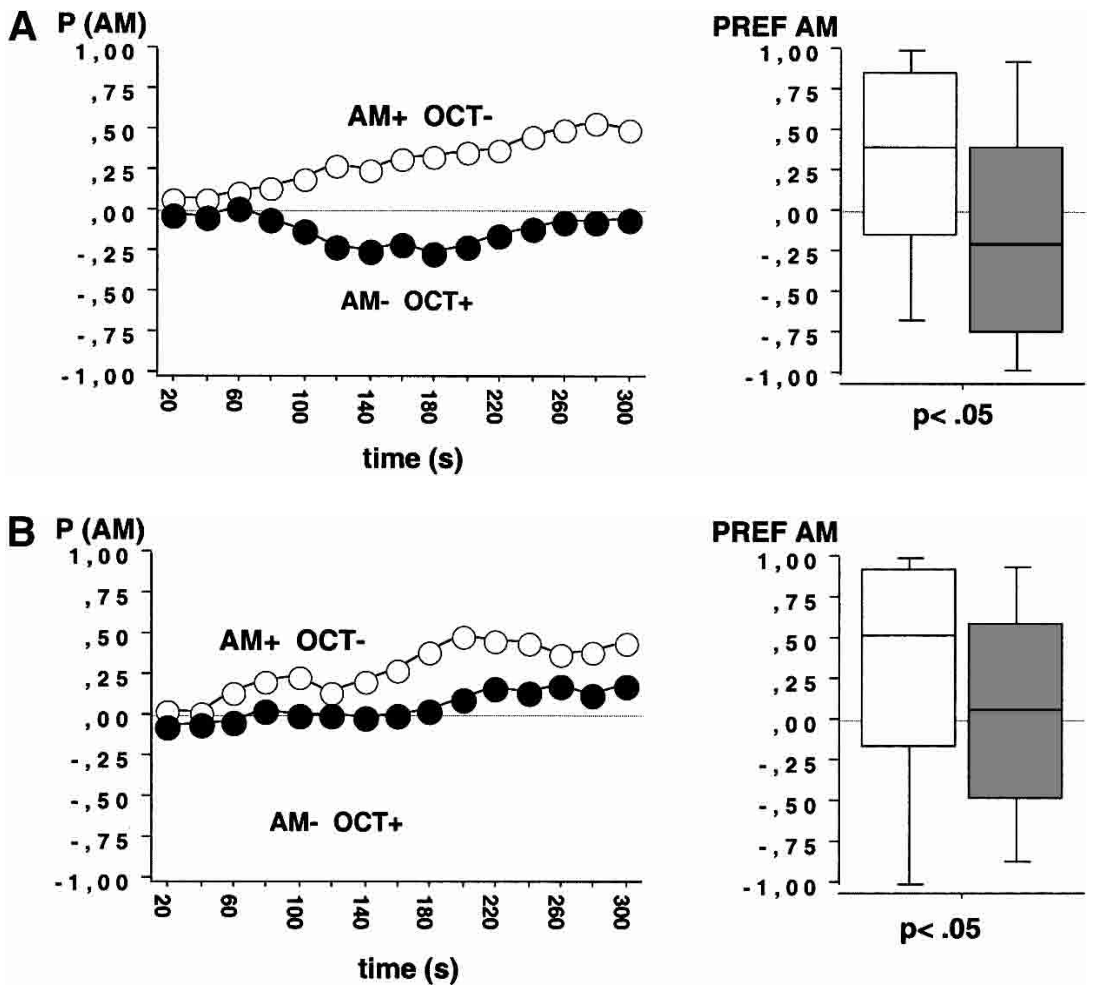

Figure 2 Test performance in Experiment 2 after training with QUI and FRU as negative (-) and positive (+) reinforcers, respectively. Animals were either trained AM+/OCT- or AM-/ $\mathrm{OCT}+$. The observed differences in test performance therefore indicate associative learning. The left panel shows the proportion of animals observed on either the AM or the OCT side (P [AM]) at each time point across the 300-sec test period; observations were made every $20 \mathrm{sec}$. The right panel shows in a box plot how odor preferences (PREF AM) are distributed across individuals. $A$ and $B$ represent repetitions of the same experiment. with AM-/OCT+ training (Fig. 2B; $\quad N_{1}=74, \quad N_{2}=81$; $U=2350 ; P<0.05)$.

Despite the match of odor preferences in Experiment 1 , animals from both treatment conditions had a tendency to prefer AM over OCT; this will also show in all following experiments. Although this effect might reduce our ability to detect associative learning, it cannot dismiss any of the associative effects observed. That is, the conclusion regarding associative learning is drawn from comparisons of individuals between treatment conditions (AM+/OCT- versus $\mathrm{AM}-/ \mathrm{OCT}+$ ) and is unaffected by any preference of $\mathrm{AM}$ over OCT; such preferences merely lead to an offset of test preference values for both groups. We can therefore safely conclude that larval Drosophila can form associations between olfactory stimuli and gustatory reinforcement.

\section{Experiment 3: Salt and Fructose as Reinforcers}

To test the general applicability of our procedure, we introduced salt $(\mathrm{NaCl}, 2 \mathrm{M})$ instead of QUI as a putative negative reinforcer. In this experiment, animals trained $\mathrm{AM}+$ / OCT - and the ones trained AM-/OCT+ showed equal preference for AM during the test (Fig. 3; $N_{1}=63, N_{2}=71$; $U=2181.5 ; P>0.05$ ), arguing that for the combination $\mathrm{NaCl} / \mathrm{FRU}$ as reinforcers, associative learning cannot be detected.

\section{Experiment 4: Spaced Training}

In an attempt to increase an associative learning effect and to uncover associative learning also for $\mathrm{NaCl} / \mathrm{FRU}$, we introduced a 1-min break (an inter-trial-interval; ITI) between training trials. Such temporally spaced training typically improves learning scores (Hintzman 1974).

As expected, we found evidence for associative learning using QUI/FRU also with such spaced training: Larvae trained AM+/OCT - showed a higher preference for AM than the animals trained reciprocally (AM-/OCT+) (Fig. 4A; $N_{1}=140$, $\left.\mathrm{N}_{2}=155 ; U=8062.5 ; P<0.05\right)$.

When using $\mathrm{NaCl} / \mathrm{FRU}$ in spaced training, we uncovered a weak, yet significant, associative learning effect also for this combination of reinforcers. The preference for AM after AM+/OCTtraining was higher than after $\mathrm{AM}-/$ OCT+ training (Fig. $4 \mathrm{~B} ; \quad N_{1}=128$, $\left.N_{2}=130 ; U=6638 ; P<0.05\right)$. From the fact that using $\mathrm{NaCl} / \mathrm{FRU}$ as reinforcers associative learning can be observed with spaced (Fig. 4B) but not with massed (Fig. 3) training, we conclude

$$
\begin{array}{lllllllllllllll} 
& E & A & R & N & I & N & G & \& & M & E & M & O & R & Y \\
\text { www.learnmem.org } & & & &
\end{array}
$$




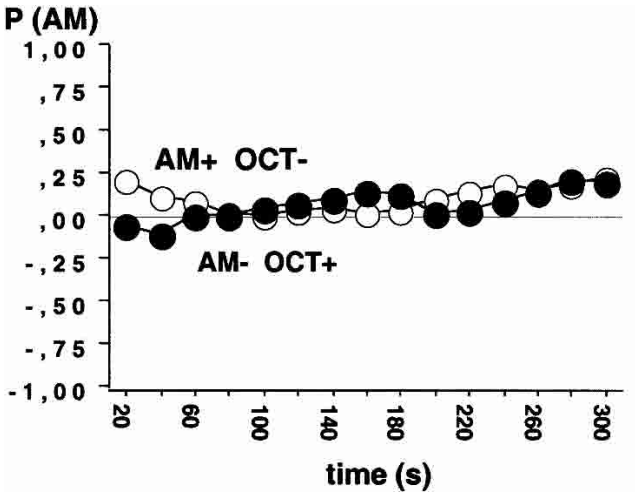

Figure 3 Test performance in Experiment 3 after training with $\mathrm{NaCl}$ and $\mathrm{FRU}$ as negative $(-)$ and positive $(+)$ reinforcers, respectively. Animals were either trained AM+/OCT- or $\mathrm{AM}-/ \mathrm{OCT}+$. As there were no differences in test performance, there is no evidence for associative learning using $\mathrm{NaCl}$ and FRU. Other details as in Figure 2.

that Drosophila larvae do, in the current paradigm, show a trial spacing effect-similar to what is regularly observed in many if not all other learning preparations (Hintzman 1974).

To gain confidence in our conclusion regarding associative learning, we repeated Experiment 4 with additional personnel in the Würzburg lab. In an attempt to increase the detectability of associative effects by reducing the experience-independent preference for $\mathrm{AM}$, we further diluted $\mathrm{AM}$ to $2 \times 10^{-2}$. Also, experimenters, mean room temperature, and a number of minor particulars of the experimental situation were different from the Fribourg experiments (see Material and Methods). Despite these differences, the outcome of Experiment $4 \mathrm{~A}$ and $\mathrm{B}$ replicated in all respects-for both combinations of reinforcers we observed a higher preference for $\mathrm{AM}$ after $\mathrm{AM}+/ \mathrm{OCT}-$ as compared with AM-/OCT+ training (Fig. 4C: for QUI/FRU: $N_{1}=92, N_{2}=94 ; U=2028 ; P<0.05$; Fig. $4 \mathrm{D}$ : for $\mathrm{NaCl} /$ FRU: $\left.N_{1}=87, N_{2}=104 ; U=3764 ; P<0.05\right)$; obviously, also in this repetition, the learning effect for $\mathrm{NaCl} / \mathrm{FRU}$ is weak. We therefore conclude that larval olfactory learning as demonstrated in the current assay is robust in terms of replicability across experimenters, laboratories, and minor experimental conditions. Importantly, under the experimental conditions chosen for Experiment $4 \mathrm{C}$, the scatter of the data is substantially reduced and the learning effect quite robust.

\section{DISCUSSION}

\section{General}

In this paper, we provide evidence for associative olfactory learning in individually assayed Drosophila larvae. This has been considered not doable because of a presumed high inter-individual variability (Dukas 1998). Nevertheless, using discriminative conditioning of odorants paired with gustatory reinforcers, we have established a learning paradigm that is, to the extent tested, reproducible across repetitions, laboratories, and experimenters. Furthermore, we have concurrently established a visual learning version of the present paradigm (B. Gerber, S. Scherer, K. Neuser, B. Michels, T. Hendel, R.F. Stocker, and M. Heisenberg, in prep.), underscoring the feasibility of this individual-based approach.

One reason why gustatory input is potent as reinforcement might be the evolutionary design of the larva as a feeding stage. Also, the intimate anatomical interplay of smell and taste in the larva (Python and Stocker 2002a,b) might facilitate associative learning between the two sensory modalities (Dukas 1998). In this sense, our paradigm seems biologically plausible and gentle, as it meets the larva's abilities. We could therefore afford providing little and short training with few animals.

For each animal, the complete training and test period in our paradigm lasts $30-50 \mathrm{~min}$; this is in the same range as needed for the procedure of Aceves-Piña and Quinn (1979) and Heisenberg et al. (1985), about half the time required in Tully et al. (1994), and more than an order of magnitude less than needed for Dukas' procedure (1998).

The current procedure requires about 70 animals per group, which is one order of magnitude less than in mass assays (Aceves-Piña and Quinn 1979: 1400; Heisenberg et al. 1985: 1800; Tully et al. 1994: 900; Dukas 1998: 1600). Both short training-time per animal and the need for relatively few animals will facilitate electrophysiological approaches on synaptic physiology (Koh et al. 2000) and recently developed in vivo imaging techniques (Fiala et al. 2002; Liu et al. 2003) as well as approaches based on the MARCM technique (Lee and Luo 2001) or on laser ablation (Schmucker et al. 1994). The current study can therefore contribute to bring together behavioral and, for example, synaptic levels of analysis; this seems desirable as the former has largely been restricted to adults and the latter to larvae.

\section{An Appreciation of Mass Versus Individual Assays}

Testing animals in mass assays has the advantage of high data acquisition speed. Therefore, mass assays seem more suitable for mutant screening. Still, testing individual larvae has advantages, too. First, fine-grained behavioral analyses are possible (Wang et al. 1997; Busto et al. 1999). Second, far fewer animals are needed (see above), a situation desirable also in its own right. Third, handling in mass assays, in particular the harvest of larvae from food bottles, is harsher and might degrade the sensitivity of behavioral tests. Fourth, despite claims to the contrary, in mass assays be-

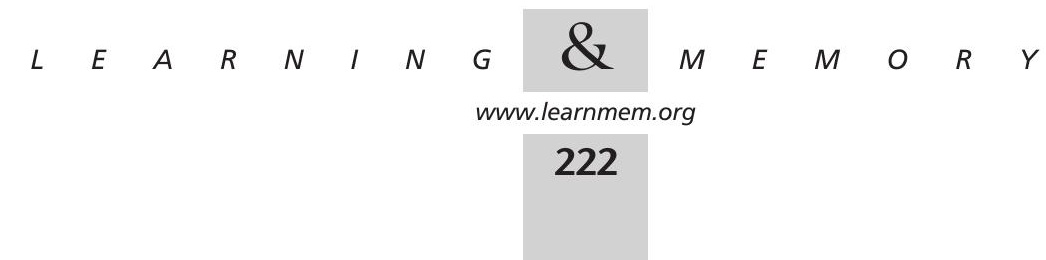



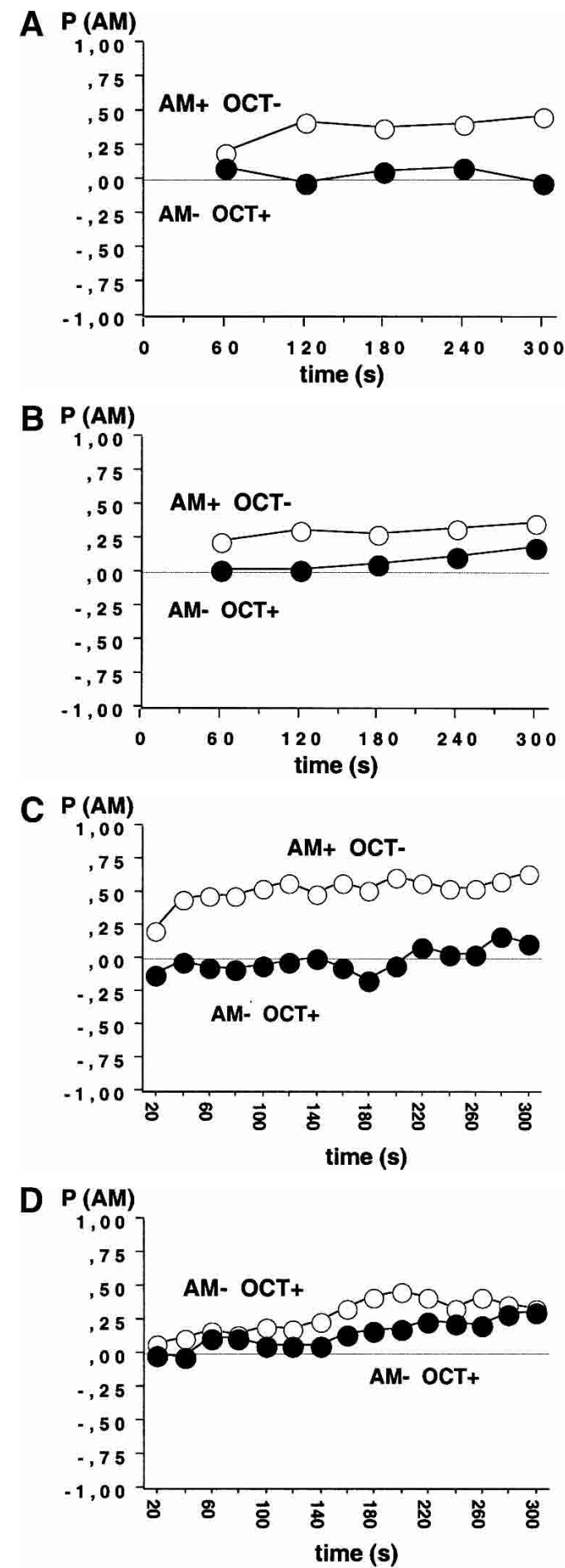

Figure 4 Test performance in Experiment 4 using temporally spaced training with an inter-trial-interval (ITI) of 1 min. Training was performed with FRU as positive (+) reinforcer and QUI $(A)$ or $\mathrm{NaCl}(B)$ as negative (-) reinforcers, respectively. Animals were either trained $\mathrm{AM}+/ \mathrm{OCT}-$ or $\mathrm{AM}-/ \mathrm{OCT}+$. The observed differences in test performance for both reinforcer combinations therefore indicate associative learning. Other details as in Figure 2; observations were made every $60 \mathrm{sec} .(C, D)$ Repetitions of Experiments $4 \mathrm{~A}$ and $4 \mathrm{~B}$ in the Würzburg lab. In $C$ and $D$, observations were made every 20 sec. For methodological differences of $A$ and $B$ versus $C$ and $D$, see text.
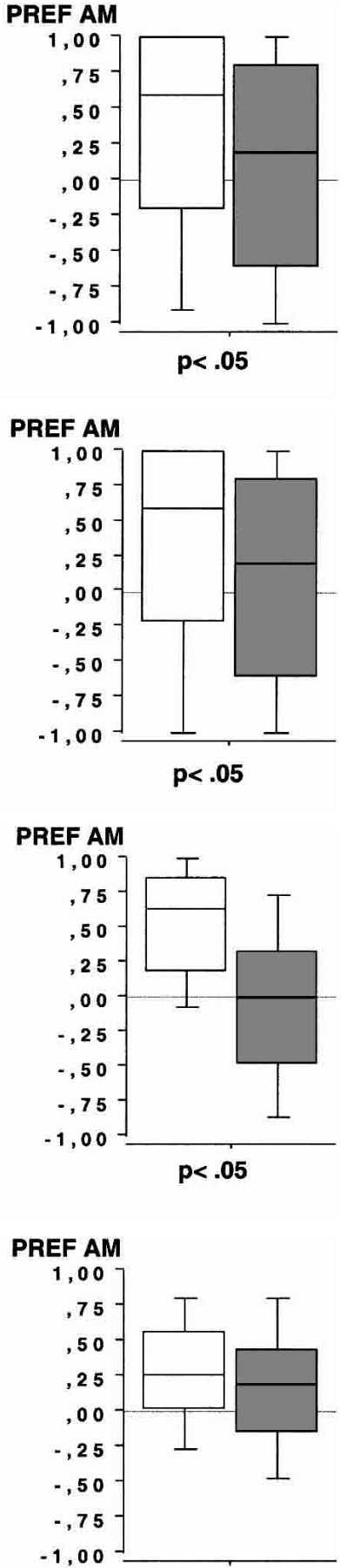

$p<.05$ havior of larvae is likely not independent of each other (see Materials and Methods).

\section{Breaks Improve Learning}

We found that learning is better when breaks are given between training trials: $\mathrm{NaCl} / \mathrm{FRU}$ as reinforcers yielded associative learning with breaks but not without them (cf. Fig. 4B with Fig. 3). Such improvement is observed almost ubiquitously in learning paradigms and might therefore reflect a basic property of memory (Hintzman 1974).

It is interesting that training with or without breaks induces different kinds of memory, dissociable, for example, in their time courses of decay and their requirement for protein synthesis (Yin et al. 1995) and nitric oxide-dependent signaling (Müller 1996). It should be possible to tackle these issues also in the Drosopbila larva; as the larva is substantially reduced in cell number, a localization of these different kinds of memory should be facilitated. This might then include a reinvestigation of the reported memory through metamorphosis (Tully et al. 1994), which so far could not be replicated (Forbes 1993).

\section{Which Associations Are Established?}

We have shown that Drosophila larvae can form associative memories using either of two combinations of reinforcers: Using QUI/FRU as reinforcers supports associative learning (Experiments 2A, 2B, 4A, and 4C), as does $\mathrm{NaCl} / \mathrm{FRU}$ (Experiments $4 \mathrm{~B}$ and $4 \mathrm{D}$ ). For $\mathrm{NaCl} / \mathrm{FRU}$, the overall reinforcing effectivity seems to be low, in particular lower than for QUI/FRU-in massed training, evidence for associative learning was observed for QUI/FRU (Experiments 2A and 2B), but not for $\mathrm{NaCl} / \mathrm{FRU}$ (Experiment 3). As FRU is present in both combinations, this might suggest that QUI is the more potent reinforcer than $\mathrm{NaCl}$-at least at the concentrations used. For $\mathrm{NaCl}$, relatively low concentrations might even have positively reinforcing effects. Clearly, only further experiments restricting the use of reinforcers to either

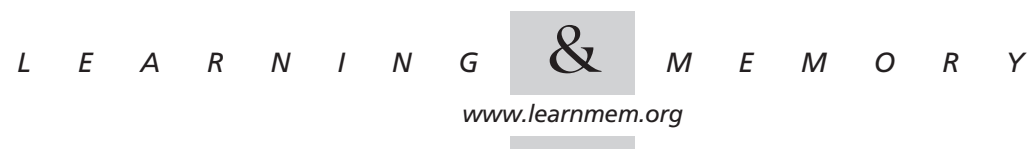


FRU, QUI, or $\mathrm{NaCl}$ alone will allow to determine whether and which of these stimuli is in itself sufficient to induce associative learning. This will be interesting in particular for FRU, as no appetitive learning has been reported for Drosophila larvae to date (see B. Gerber, S. Scherer, K. Neuser, B. Michels, T. Hendel, R.F. Stocker, and M. Heisenberg, in prep.).

In any event, it will be interesting to see whether, using only one reinforcer, memory is-in terms of localization and internal reinforcement signals involved (Hammer and Menzel 1995; Waelti et al. 2001)_dissociable from memories established by other reinforcers. In mammals, a dissociation of reinforcement systems is suggested by the preferential activation of midbrain dopamine neurons by appetitive rather than aversive reinforcers (Mirenowicz and Schultz 1996). In fly larvae, inquieries into the reinforcement systems (M. Schwaerzel, M. Monastirioti, H. Scholz, F. Friggi-Grelin, S. Birman, and M. Heisenberg, in prep.) as well as localization analyses (Zars et al. 2000) should be facilitated by the cellular simplicity of the larval chemosensory system (Python and Stocker 2002a,b). Together with the concurrently developed visual version of the present learning paradigm (B. Gerber, S. Scherer, K. Neuser, B. Michels, T. Hendel, R.F. Stocker, and M. Heisenberg, in prep.), it will be interesting to also compare the organization of olfactory versus visual memories established by the same reinforcers.

\section{Applications of the Current Paradigm in Olfactory Research}

The current learning paradigm might be useful in Drosophila olfactory research in general. That is, it is the function of sensory systems to tell apart different inputs and to allow differential behavior. Testing hypotheses about sensory system function, for example, about the role of any given olfactory receptor gene, must therefore involve demonstrating a role in telling apart different inputs. Cross adaptation studies (Cobb and Domain 2000) can beautifully demonstrate the potential for telling apart inputs. Whether or not such potential is used by the animals, however, will depend on demonstrating differential behavior. The current paradigm might be useful in this respect. As it demands relatively little manual skill and technical equipment, it will hopefully be easy to adapt and prove useful to the scientific community.

\section{ACKNOWLEDGMENTS}

We thank the Volkswagen Foundation for giving the opportunity to initiate this research program (grant I/76 240 to B.G.). Current support comes from the Deutsche Forschungsgemeinschaft (SFB 554, via M. Heisenberg) and the Swiss National Fund (31-52639.97 and 31-063447.00, to R.F.S.). Many thanks to the members of the Würzburg and Fribourg laboratories, especially T. Zars (University of Missouri, Columbia, MO), N. Gendre, and G. Heimbeck (BioRad, Basel, Switzerland) for their various helpful contributions to this study; and T. Hendel and B. Michels for help with the experiments. The critical remarks of M. Heisenberg, T. Hendel, B. Michels, K Kaun, M. Sokolowski, and T. Zars on earlier versions of this manuscript are gratefully acknowledged.

The publication costs of this article were defrayed in part by payment of page charges. This article must therefore be hereby marked "advertisement" in accordance with 18 USC section 1734 solely to indicate this fact.

\section{REFERENCES}

Aceves-Piña, E.O. and Quinn, W.G. 1979. Learning in normal and mutant Drosophila larvae. Science 206: 93-96.

Boeckh, J., Distler, P., Ernst, K.D., Hösl, M., and Malun, D. 1990. Olfactory bulb and antennal lobe. In Chemosensory information processing (ed D. Schild), NATO ASI Series H 39, pp. 201-228. Springer, Berlin-Heidelberg-New York.

Busto, M., Iyengar, B., and Campos, A.R. 1999. Genetic dissection of behavior: Modulation of locomotion by light in the Drosophila melanogaster larva requires genetically distinct visual system functions. J. Neurosci. 19: 3337-3344.

Cobb, M. 1999. What and how do maggots smell? Biol. Rev. 74: 425-459.

Cobb, M. and Domain, I. 2000. Olfactory coding in a simple nervous system: Adaptation in Drosophila larvae. Proc. R. Soc. London (B) 267: 2119-2125.

Dukas, R. 1998. Ecological relevance of associative learning in fruit fly larvae. Behav. Ecol. Sociobiol. 19: 195-200.

Fiala, A., Spall, T., Diegelmann, S., Eisermann, B., Sachse, S., Devaud, J.-M., Buchner, E., and Galizia, C.G. 2002. Visualization of olfactory information in projection neurons using genetically expressed cameleon in Drosophila melanogaster. Curr. Biol. 12: 1877-1884

Forbes, B. 1993. "Larval learning and memory in Drosophila melanogaster." Diploma thesis. Institut für Genetik, Universität Würzburg.

Gordesky-Gold, B., Warrick, J.M., Kutzler, D.P., Neal, K.C., Coughlin, M., and Tompkins, L. 1996. Interstrain variability of larval photokinesis in Drosophila melanogaster. Behav. Genet. 26: 49-54

Hammer, M. and Menzel, R. 1995. Learning and memory in the honeybee J. Neurosci. 15: 1617-1630.

Heimbeck, G., Bugnon, V., Gendre, N., Häberlin, C., and Stocker, R.F. 1999. Smell and taste perception in Drosophila melanogaster larva: Toxin expression studies in chemosensory neurons. J. Neurosci. 19: 6599-6609.

Heisenberg, M., Borst, A., Wagner, S., and Byers, D. 1985. Drosophila mushroom body mutants are deficient in olfactory learning. $J$. Neurogenet. 2:1-30.

Heisenberg, M., Wolf, R. and Brembs, B. 2001. Flexibility in a single behavioral variable of Drosophila. Learn. E Mem. 8: 1-10.

Hildebrand, J.G. and Shepherd, G.M. 1997. Mechanisms of olfactory discrimination: Converging evidence for common principles across phyla. Ann. Rev. Neurosci. 20: 595-631.

Hintzman, D.L. 1974. Theoretical implications of the spacing effect. In Theories in cognitive psychology. The Loyola Symposium (ed. R.L. Solso), pp. 77-99. Erlbaum, Hillsdale, N.J.

Kankel, D.R., Ferrus, A., Garen, S.H., Harte, P.J., and Lewis, P.E. 1980. The structure and development of the nervous system. In The genetics and biology of Drosophila (eds. M. Ashburner, and T.R.F. Wright), Vol. 2, pp. 295-368. Academic Press, London-New York-San Francisco.

Koh, Y.H., Gramates, L.S., and Budnik, V. 2000. Drosophila larval neuromuscular junction: Molecular components underlying synaptic plasticity. Microscopy Res. Tech. 49: 14-25.

Lee, T. and Luo, L. 2001. Mosaic analysis with a repressible cell marker (MARCM) for Drosophila neural development. Trends Neurosci. 24: 251-254.

Lilly, M. and Carlson, J.R. 1990. Smellblind: A gene required for Drosophila olfaction. Genetics 124: 293-302.

Liu, L., Yermolaieva, O., Johnson, W.A., Abboud, F.M., and Welsh, M.J.

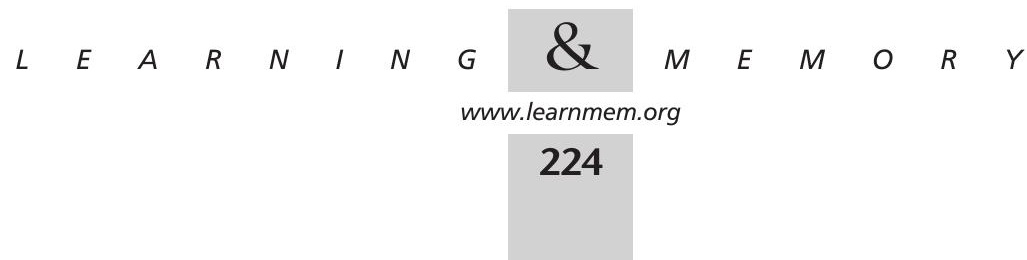


2003. Identification and function of thermosensory neurons in Drosophila larvae. Nat. Neurosci. 6: 267-273.

Mirenowicz, J. and Schultz, W. 1996. Preferential activation of midbrain dopamine neurons by appetitive rather than aversive stimuli. Nature 379: 449-451.

Mitchell, B.K., Itagaki, H., and Rivet, M.-P. 1999. Peripheral and central structures involved in insect gustation. Microscopy Res. Tech. 47: 401-415.

Müller, U. 1996. Inhibition of nitric oxide synthase impairs a distinct form of long-term memory in the honeybee, Apis mellifera. Neuron 16: 541-549.

Oppliger, F.Y., Guerin, P.M., and Vlimant, M. 2000. Neurophysiological and behavioural evidence for an olfactory function for the dorsal organ and a gustatory one for the terminal organ in Drosophila melanogaster larvae. J. Insect Physiol. 46: 135-144.

Python, F. and Stocker, R.F. 2002a. Adult-like complexity of the larval antennal lobe of $D$. melanogaster despite markedly low numbers of odorant receptor neurons. J. Compar. Neurol. 445: 374-387.

2002b. Immunoreactivity against choline acetyltransferase, $\gamma$-aminobutyric acid, histamine, octopamine, and serotonin in the larval chemosensory system of Drosophila melanogaster. J. Compar. Neurol. 453: 157-167.

Rubin, G.M., Yandell, M.D., Wortman, J.R., Gabor Miklos, G.L., Nelson, C.R., Hariharan, I.K., Fortini, M.E., Li, P.W., Apweiler, R., Fleischmann, W., et al. 2000. Comparative genomics of the eukaryotes. Science 287: 2204-2215.

Sawin-McCormack, E.P., Sokolowski, M.B., and Campos, A.R. 1995. Characterization and genetic analysis of Drosophila melanogaster photobehavior during larval development. J. Neurogenet. 10: 119-135.

Schmucker, D., Su, A.L., Beerman, B., Jackle, H., and Jay, D.G. 1994. Chromophore-assisted laser inactivation of patched protein switches cell fate in the larval visual system of Drosophila. Proc. Nat. Acad. Sci. 91: 2666-2668.

Scott, K., Brady, R.J., Cravchik, A., Morozov, P., Rzhetsky, A., Zuker, C., and Axel, R. 2001. A chemosensory gene family encoding candidate gustatory and olfactory receptors in Drosophila. Cell 104: 661-673.

Singh, R.N. 1997. Neurobiology of the gustatory systems of Drosophila and some terrestrial insects. Microscopy Res. Tech. 39: 547-563.

Singh, R.N. and Singh, K. 1984. Fine structure of the sensory organs of
Drosophila melanogaster Meigen larva (Diptera: Drosophilidae). Int. J. Insect Morphol. Embryol. 13: 255-273.

Smith, D.P. 2001. Drosophila gustation: A question of taste. Neuron 29: 551-554.

Sokolowski, M.B. 2001. Drosophila: Genetics meets behavior. Nat. Rev. Genet. 2: 879-890.

Stocker, R.F. 1994. The organization of the chemosensory system in Drosophila melanogaster: A review. Cell \& Tissue Res. 275: 3-26.

Stocker, R.F. 2001. Drosophila as a focus in olfactory research: Mapping of olfactory sensilla by fine structure, odor specificity, odorant receptor expression, and central connectivity. Microscopy Res. Tech. 55: 284-296.

Tissot, M., Gendre, N., Hawken, A., Störtkuhl, K.F., and Stocker, R.F. 1997. Larval chemosensory projections and invasion of adult afferents in the antennal lobe of Drosophila. J. Neurobiol. 32: 281-297.

Tully, T., Cambiazo, V., and Kruse, L. 1994. Memory through metamorphosis in normal and mutant Drosophila. J. Neurosci. 14: $68-74$

Vosshall, L.B. 2001. The molecular logic of olfaction in Drosophila. Chem. Senses 26: 207-213.

Waddell, S. and Quinn, W.G. 2001. Flies, genes and learning. Ann. Rev. Neurosci. 24: 1283-1309.

Waelti, P., Dickinson, A., and Schultz, W. 2001. Dopamine responses comply with basic assumptions of formal learning theory. Nature 412: 43-48.

Wang, J.W., Sylwester, A.W., Reed, D., Wu, D.-A.J., Soll, D.R. and Wu, C.-F. 1997. Morphometric description of the wandering behavior in Drosophila larvae: Aberrant locomotion in $\mathrm{Na}+$ and $\mathrm{K}+$ channel mutants revealed by computer- assisted motion analysis. J. Neurogenet. 11: $231-254$.

Yin, J.C.P., Del Vecchio, M., Zhou, H., and Tully, T. 1995. CREB as a memory modulator: Induced expression of a dCREB2 activator isoform enhances long-term memory in Drosophila. Neuron 81: 107-115.

Zars, T. 2001. Behavioral functions of the insect mushroom bodies. Curr. Opin. Neurobiol. 10: 790-795.

Zars, T., Fischer, M., Schulz, R., and Heisenberg, M. 2000. Localization of a short-term memory in Drosophila. Science 288: 672-675.

Received November 12, 2002; accepted in revised form March 18, 2003. 


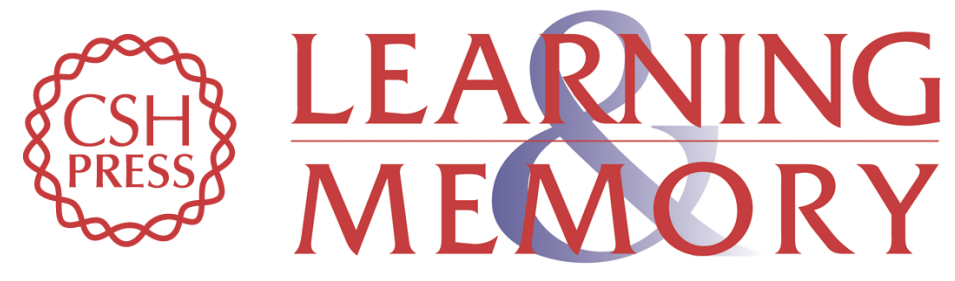

\section{Olfactory Learning in Individually Assayed Drosophila Larvae}

Sabine Scherer, Reinhard F. Stocker and Bertram Gerber

Learn. Mem. 2003, 10:

Access the most recent version at doi:10.1101/lm.57903

References This article cites 38 articles, 9 of which can be accessed free at: http://learnmem.cshlp.org/content/10/3/217.full.html\#ref-list-1

License

Email Alerting Receive free email alerts when new articles cite this article - sign up in the box at the Service top right corner of the article or click here. 